\title{
Poverty and mental health in Aboriginal Australia
}

\author{
Jonathan Laugharne
}

\section{Aboriginal health: an overview}

When the Australian Governor General, Sir William Deane, referred in a speech in 1996 to the "appalling problems relating to Aboriginal health" he was not exaggerating. The Australia Bureau of Statistics report on The Health and Welfare of Australia's Aboriginal and Torres Strait Islander Peoples (McLennan \& Madden, 1997) outlines the following statistics. The life expectancy for Aboriginal Australians is 15 to 20 years lower than for non-Aboriginal Australians, and is lower than for most countries of the world with the exception of central Africa and India. Aboriginal babies are two to three times more likely to be of lower birth weight and two to four times more likely to die at birth than nonAboriginal babies. Hospitalisation rates are two to three times higher for Aboriginal than nonAboriginal Australians. Death rates from infectious diseases are 15 times higher among Aboriginal Australians than non-Aboriginal Australians. Rates for heart disease, diabetes, injury and respiratory diseases are also all higher among Aboriginals - and so the list goes on. It is fair to say that Aboriginal people have higher rates for almost every type of illness for which statistics are currently recorded.

In regards to the mental health of Aboriginal Australians there is a notable lack of good quality data. In compiling their report Ways Forward: The National Consultancy Report on Aboriginal and Torres Strait Islander Mental Health, Swan \& Raphael (1995) found high levels of unmet need in relation to mental health. They suggested that Aboriginal people "suffer mental health problems such as depression at a very high rate, compared to non-Aboriginal people and that rates of self-harm and suicide are higher and that substance abuse, domestic violence, child abuse and disadvantage are contributing additional risk factors. Trauma and grief were seen as overwhelming problems". Data available for public hospital separations among Aboriginal people in Western Australia, Northern Territory, Queensland and South Australia indicate three times the average population rates for mental disorders. Aboriginal people have higher rates of hospitalisation for self-harm behaviour, particularly self-inflicted cutting or piercing. Suicide rates across all age groups are twice as high for Aboriginal males as for non-Aboriginal males. Also more indigenous people are more likely to drink alcohol at dangerous levels than non-indigenous people and also have higher rates of marijuana usage (McLennan \& Madden, 1997).

\section{Material poverty}

Census data from 1991 and 1994 indicate that indigenous households receive substantially less annual income than non-indigenous households. In addition, 55\% of Aboriginal Australians over the age of 15 years reported Government payments as their main source of income in the 1994 census. One important source of employment is through Community Development Employment Projects, which is a particularly important source of income and work in rural areas. In terms of education. Aboriginal people are less likely to have post-secondary school qualifications thus putting them at a disadvantage with respect to employment opportunities which do exist.

Indigenous households are twice as likely as other Aboriginal households to need housing assistance. Almost four in 10 Aboriginal households were estimated to have either insufficient income to meet basic needs (even before taking housing into account) or not enough income to afford adequate housing. Indigenous people are over-represented among the service users of the support of the accommodation assistance programme which provides services for people with acute housing needs such as homelessness (McLennan \& Madden, 1997).

It is reasonably clear therefore from the data that the Aboriginal population is materially impoverished. This impression is confirmed by the fact that the international aid organisation World Vision, which works primarily in developing countries, has shown interest in developing projects in certain Aboriginal communities. The implications of lower income and poor education on employment, housing. sanitation and 
nutrition provide an understandable link into the widespread health problems previously outlined. There is also sufficient evidence of the impact of material poverty on a population's mental health. Poverty has been identified by the World Health Organization as a key social initiator of mental ill health (Desjarlais \& Eisenberg, 1995) while Henderson et al (1998) have recently summarised the evidence for the impact of unemployment on mental health indicators and the relationship between overcrowded accommodation and council housing and higher psychiatric prevalence rates. Wilkinson (1989) has suggested the extent of inequality between socio-economic groups leading to reduced social cohesion may be significant in increasing morbidity. Each of these aspects of poverty are highly relevant to the Aboriginal situation.

\section{Cultural and service delivery poverty}

Saraceno \& Barbui (1997), in an article on poverty and mental illness, have suggested that two aspects of impoverishment which are often overlooked in the context of mental illness are cultural poverty and service delivery poverty. These are both worthy of serious consideration within the Aboriginal context. The loss of traditional language, values, rituals and understandings which many Aboriginal people have experienced since colonisation leaves many modern Aboriginal people struggling to find the clear identity within modern Australian culture. This seems particularly true for those living in urban areas and for the younger generation. Thus rapid cultural change has undoubtedly had an important impact on mental health for Aboriginal people. It is also worth noting, however, that one aspect of Aboriginal culture which is still reasonably intact is the importance of the extended family grouping and as research has shown in other contexts the support of such family structures may be of important therapeutic benefit for the mentally ill (Jablensky et al, 1992).

It does not take a great deal of reflection to realise that Aboriginal Australians also suffer from poverty of psychiatric service delivery. A larger proportion of indigenous Australians live in rural areas, sometimes remote, where health services are relatively scant. Thus treatment availabilities both out-patient and in-patient are often limited. Staff recruitment and retention is a problem and the 'style of work' of practitioners may not be culturally appropriate for Aboriginal people. Thus there is often a problem with availability, acceptability or accessibility of mental health services. In the Ways Forward report, Swan \& Raphael (1995) noted that indigenous people perceived mainstream health services as failing them. These authors put forward a number of key principles that should guide the development of mental health services for Aboriginal people which included the concept of health as holistic, the right to self-determination and the recognition of the impact of history and trauma and loss. The service development in which I have been involved has been one of the few initiatives which have so far attempted to embody these key principles within service development. Unfortunately, other such initiatives remain at the policy and planning stage at present. This certainly is a significant challenge for mental health service delivery planners over the next 5-10 years as they seek to integrate these principles into the delivery of services around Australia.

\section{Conclusions}

To consider poverty in isolation when considering the current situation of Aboriginal people in Australia is somewhat artificial. The interrelationships between poverty in its various aspects, unemployment, housing, nutrition. domestic violence, alcohol and substance misuse and health are complex. However, it appears to me that the Aboriginal context does exemplify the links between poverty and mental ill health which have been outlined in the world literature. It seems particularly sad that such a relationship can be identified in a community living within an affluent developed country such as Australia. It is to be hoped that through the political will to improve economic prospects for Aborigines and through the provision of improved culturally appropriate mental health services that this situation will eventually improve so that Aboriginal Australians can enjoy equitable physical and mental health with other Australians.

\section{References}

DESJARLAIS, R. \& EISENBERG, L. (eds) (1995) Executive summary: a call for a United Nations year of mental health and a World Vision Organisation decade of mental health. In World Mental Health: Problems and Priorities in Low-Income Countries. New York: Oxford University Press.

Henderson, C., Thornicroft, G. \& Glover, G. (1998) Inequalities in mental health. British Journal of Psychiatry. 173, 105-109.

JABLENSKY, A., SARTORIUS, N., ERNBERG, G., et al (1992) Schizophrenia: Manifestations Incidence and Course in Different Cultures. A World Health Organization 10Country Study. Psychological Medicine, Monograph Suppl. 20. Cambridge: Cambridge University Press. 
MCLENNAN, W. \& MADDEN, R. (1997) The Health and Welfare of Australia's Aboriginal and Torres Strait Islander Peoples. Canberra: Australia Bureau of Statistics, Australian Government Publishing Service.

SARACENO, B. \& BARBUI, C. (1997) Poverty and mental illness. Canadian Journal of Psychiatry, 42, 285-290.

SWAN, P. \& RAPHAEL. B. (1995) Ways Forwand: The National Consultancy Report on Aboriginal and Torres Strait Islander Mental Health. Canberra: Australian Government Publishing Service.
WiLkinson, R. G. (1989) Class mortality differentials. income distribution and trends in poverty, 1921-1981. Journal of Social Policy. 18, 307-335.

Jonathan Laugharne, Regional Psychiatrist, Maga-Barndi Health Unit, Geraldton Regional Aboriginal Medical Service, PO Box 1689, Geraldton WA 6531

\section{Promoting Mental Health Internationally}

Editors: Leon Eisenberg, David Goldberg, Giovanni di Girolamo and John Cooper

To mark the retirement of Dr Norman Sartorius in 1974 from his post as Director of the Division of Mental health of the World Health

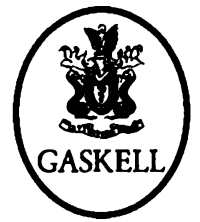
Organisation, the editors (all long-standing advisors and collaborators with the WHO programme) have brought together contributions from a mixture of advisors, collaborators and WHO staff members. The chapters provide descriptions and commentaries on the main aspects of the last 30 years of the WHO programme in mental health. The major topics and issues include the cross-cultural epidemiology and outcome of persons with serious mental illnesses, cross-cultural aspects of problems related to the misuse and control of alcohol and drugs of dependency, the role of psychiatry in primary care, and the development of a 'common language' for psychiatrists and mental health workers.

July 1999, Paperback, 192pp, ISBN 1901242 37 4, £25.00

Available from Book Sales, Royal College of Psychiatrists, 17 Belgrave Square, London SWIX 8PG

$\mathrm{Tel}+44$ (0) 1712352351 (extension 146) $9.30 \mathrm{am}-2$ pm, Fax +44 (0) 1712451231

hHp://www.rcpsych.ac.uk 